\title{
Software e prática pedagógica na EB Estudo de caso em contexto brasileiro
}

\author{
Cassiane Beatrís Pasuck Benassi* \\ Juliana Alves da Silva Ubinski* \\ Dulce Maria Strieder ${ }^{* * *}$
}

\begin{abstract}
RESUMO: A reflexão do tema é alvo central deste artigo a partir de um estudo de caso cujo objetivo pretendeu verificar, na educação básica do município de Cascavel-PR, como os professores visualizam a inclusão de tecnologias na prática docente, enfatizando o uso de software. Foi possível perceber a falta de conhecimento e condições para que o professor utilize recursos tecnológicos, sendo a formação continuada e o investimento em infraestrutura os principais obstáculos para a mudança da realidade.
\end{abstract}

Palavras-chave: Educação Básica. Softwares educacionais. Ação docente e informática.

\section{Software and pedagogical practice in Basic Education}

Case study in Brazilian context

\begin{abstract}
A thematic reflection is the central objective of this article, based on a case study whose objective was to verify how teachers visualize the inclusion of technologies in teaching practice emphasizing the use of software, within the basic education system
\end{abstract}

* Mestra em Educação pela Universidade Estadual do Oeste do Paraná é graduada em Matemática com habilitação para Física. Atualmente é professora de física e matemática na rede pública e privada de Cascavel. Participa do Grupo de Formação de Professores no Ensino de Ciências e Matemática pela Universidade Estadual do Oeste do Paraná. Cascavel/PR - Brasil. E-mail: <cassibp@hotmail.com>.

** Mestra em Educação pela Universidade Estadual do Oeste do Paraná (Unioeste) e especialista em Ensino de Ciências e Matemática. Atualmente está vinculada à Secretaria de Estado da Educação do Paraná. Cascavel/PR - Brasil. E-mail: <juliana_ubinski@hotmail.com>.

*** Doutora em Educação pela Universidade de São Paulo, atualmente é docente da Universidade Estadual do Oeste do Paraná onde atua na área de física no Centro de Ciências Exatas e Tecnológicas e no Programa de Pós-Graduação em Educação (mestrado) do Centro de Educação, Comunicação e Artes. Cascavel/PR Brasil. E-mail:<dulce.strieder@unioeste.br>. 
in the municipality of Cascavel - PR. Lack of knowledge and practical conditions were evident in the teachers' use of technological resources, meaning that lack of continued training and investment in infrastructure are the main obstacles for changing this reality.

Keywords: Basic education. Educational software. Teaching and computer science.

\section{Software y práctica pedagógica en la Escuela Básica}

Estudio de caso en el contexto brasileño

RESUMEN: La reflexión sobre el tema es el objetivo central de este artículo a partir de un estudio de caso cuyo objetivo fue verificar, en la educación básica del municipio de Cascavel, estado de Paraná, cómo los profesores ven la inclusión de tecnologías en la práctica docente, enfatizando el uso de programas informáticos. Se pudo notar la falta de conocimiento y condiciones para que el profesor utilice recursos tecnológicos, y la falta de formación continua y de inversión en infraestructura son los principales obstáculos para cambiar la realidad.

Palabras clave: Educación Básica. Programas informáticos educativos. Acción docente e informática.

\section{Logiciels et pratique pédagogique en éducation basique \\ Étude de cas dans un contexte brésilien}

RÉSUMÉ: Cet article analyse une étude de cas dont l'objectif était de vérifier comment les professeurs perçoivent l'inclusion des technologies, en particulier des logiciels, dansleur pratique enseignante, au sein de l'éducation basique de la ville de Cascavel dans le Parana. On a pu voir que le professeur manque de connaissances mais aussi de conditions pour l'utilisation des ressources technologiques, les obstacles principaux à celles-ci, empêchant un changement de réalité, resident dans la formation continue et dans l'investissementen infrastructures.

Mots-clés: Éducation basique. Logiciels éducatifs. Enseignement et Informatique. 


\section{Introdução}

s atividades humanas estão permeadas pela constante criação e uso de tecno-
logias, desde as mais simples até os aparatos sofisticados, buscando facilitar
a realização de determinadas tarefas. Em diferentes áreas do conhecimento, é impossível não pensar em utilizar as tecnologias disponíveis para realização de procedimentos. No campo da Medicina, por exemplo, é necessário ter conhecimento sobre as novas possibilidades de procedimentos cirúrgicos e diagnósticos que são possibilitados por uma gama de aparatos tecnológicos.

Na área da Educação, a inserção de novas tecnologias pode representar um contributo para o ensino e a aprendizagem dos alunos, sendo que a utilização desses recursos dependerá da concepção e formação do professor para inserir esses recursos em suas aulas. Sendo assim, é importante conhecer a realidade do ensino no tocante a utilização de tecnologias, para assim, verificar se há impacto no aprendizado dos alunos.

Dentre as tecnologias disponíveis que podem ser utilizadas na escola, destaca-se o uso de softwares e simuladores. Assim, a reflexão acerca da utilização de softwares no ambiente escolar é alvo central do presente texto que foi elaborado a partir de um estudo cujo objetivo pretendeu verificar através de questionários como os professores atuantes na Educação Básica brasileira visualizam a inclusão de tecnologias em sua prática docente enfatizando o uso de softwares. Trabalhos desta natureza são importantes, uma vez que, no contexto brasileiro, grandes mudanças são necessárias para a efetiva inserção das tecnologias da informação e comunicação no espaço escolar (LEITE; RIBEIRO, 2012), ainda que esforços políticos tenham sido realizados para este fim (BIELSCHOWSKY, 2009). No Brasil, segundo Valente (2012) ainda que o computador faça parte do cotidiano particular de muitos professores, este em sua maioria sente dificuldades de desenvolver aulas onde tal tecnologia gere um estímulo adicional para a aprendizagem.

\section{Contextualização sobre as tecnologias no ensino}

Antes de nos remetermos aos dados da pesquisa, faz-se necessário uma contextualização sobre como está ocorrendo à inserção de tecnologias no ambiente escolar de muitas escolas brasileiras.

\section{A presença das tecnologias no ambiente escolar}

As tecnologias interativas, utilizadas como ferramentas pedagógicas, fazem referência a meios instrucionais como: programas educacionais interativos, CD-ROM, vídeo laser interativo, hipertexto, hipermídia, correio eletrônico, realidade virtual, programas 
simuladores e recursos da Internet. Trata-se de uma realidade à qual todos os profissionais da área pedagógica precisam se adequar para contribuir de forma significativa para a formação do indivíduo (FERREIRA, 1998).

Na década de 1970, foram realizadas as primeiras experiência em relação à inserção de tecnologias no ensino. Na época, as previsões para melhoria do processo de ensino e de aprendizagem através do uso de computadores eram as mais otimistas possíveis. No entanto, após quatro décadas, ainda não foi possível atingir a excelência na aplicação desses recursos no ensino brasileiro (PEREIRA, 2011). O mesmo autor menciona ainda que, na década de1990, alguns fatores que interferiam na dificuldade de se modernizar o ensino, já eram discutidos e começavam a surgir propostas para que esses problemas fossem superados. Segundo o autor, os principais pontos a serem considerados eram a falta de recursos financeiros e a formação inadequada dos professores.

Ainda que desde cedo as dificuldades fizessem parte das tentativas de inovação, as vantagens do processo continuaram a ser discutidas. Neste sentido, Chaves (1998) destaca algumas vantagens da inserção do computador no ambiente escolar enumerando que este: viabiliza o ensino à distância; é mais amistoso para o aluno do que o livro; fica sob o comando do aluno; está sempre disponível para o aluno, independente do seu ritmo de aprendizado; possui infinitas possibilidades de variação, o computador de amanhã será diferente do computador de hoje; não há barreiras geográficas e temporais para o conhecimento, visto o crescimento de comunidades virtuais de trabalho e aprendizado. Por outro lado, Miranda (2007) destaca que há casos em que o professor acaba desqualificando a aprendizagem mais estruturada e formal, acreditando que a aprendizagem passa a ocorrer por mera "transferência analógica", acarretando em algumas desilusões frente ao uso de tecnologias. Mas se o professor souber utilizar algumas ferramentas tecnológicas e incorporá-las a sua prática pedagógica, poderá então contribuir para a aprendizagem significativa de seus alunos.

A utilização de diferentes tecnologias na escola aproxima do aluno muitos caminhos a serem percorridos até o conhecimento; ao professor cabe auxiliá-lo na escolha mais adequada para atingir esse conhecimento. É o docente que vai dinamizar todo o processo por intermédio das ferramentas à disposição, envolvendo o discente na aprendizagem. O uso de tecnologias na educação, de acordo com Ferreira (2002), traz muitas vantagens, dentre elas: status social por possibilitar a experimentação de crianças e adolescentes de um conhecimento não dominado por adultos ao seu redor, bem como fornecer respostas instantâneas no uso de comandos que, quando acionados erradamente, produzem resultado imediato, levando o indivíduo a refletir sobre o erro e decidir sobre o novo caminho a tomar para a solução do problema. Ainda para Ferreira (2002), o aluno deixa de ver o erro como um fracasso, mas sim como uma oportunidade de repensar sobre novas ações. As tecnologias contribuem para melhorar o raciocínio, a criatividade e outros aspectos do desenvolvimento intelectual, além da autonomia na aprendizagem. 
Os computadores são peças de destaque no progresso tecnológico nas diferentes áreas de atuação em que estão inseridos. Apesar de estarmos em momento em que o progresso científico e tecnológico é acelerado, e que softwares e aplicativos se tornam obsoletos rapidamente, muitas das escolas brasileiras ainda segue o mesmo padrão: cadeiras, mesas, quadros, giz e livros. A expectativa é a chegada do momento em que haverá um computador para cada estudante. Embora se mencione que alunos e professores tenham acesso a diferentes tecnologias no processo de ensino e aprendizagem, não se defende aqui a exclusão de recursos pedagógicos utilizados com maior frequência, tais como livros e quadro negro. $\mathrm{O}$ ideal seria que o professor tivesse todo esse aparato disponível para poder incorporá-los em sua prática docente, de acordo com as especificidades de sua aula (ROSA, 2013).

\section{A utilização de softwares em sala de aula}

Segundo Gontijo e Costa (2008), a busca por melhorar o aprendizado tem feito surgir várias iniciativas, dentre elas, o incentivo ao uso de tecnologias nas escolas. A utilização de tecnologias vem assumindo papel importante na educação. $\mathrm{O}$ aparato tecnológico disponível no mercado é muito diversificado. Dentre as ferramentas que o professor pode incorporar em sua prática pedagógica destacam-se os softwares educativos. Os softwares voltados para o ensino têm ganhado cada vez mais espaço em diferentes áreas do conhecimento

Um dos conceitos mais aplicados para software define-o como um complemento lógico que "[...] compreende um conjunto de programas escritos em uma linguagem de programação que ativa o computador conforme o objetivo determinado" (MATHIS, 2011). Os softwares educacionais são programas para o computador destinados para o ensino, sendo ou não desenvolvidos para essa função. No entanto, é necessário que o professor fique atento à filosofia educacional adotada para o desenvolvimento do programa, e a posição que o aluno é colocado neste contexto, para que não haja conflitos com a filosofia educacional da escola, mas para que todo o processo seja coerente e que a aprendizagem seja potencializada. É importante que se ultrapasse o limite do uso pelo uso, sem consciência da interface metodológica, o que pode dificultar ao invés de facilitar a aprendizagem.

Morais (2003), assim como Mathis (2011), menciona que o professor pode utilizar em sua prática pedagógica softwares que não foram desenvolvidos especificamente para o ensino. No entanto, o autor traz importantes características que um software educativo possui, o que o diferencia dos demais, como: definição e presença de uma fundamentação pedagógica que permeie todo o seu desenvolvimento; finalidade didática, por levar o aluno a "construir" conhecimento relacionado com seu currículo escolar; interação de uso, uma vez que não se devem exigir do aluno conhecimentos computacionais prévios, 
mas permitir que qualquer aluno, mesmo que em um primeiro contato com a máquina, “[...] seja capaz de desenvolver suas atividades; atualização quanto ao estado da arte, ou seja, o uso de novas técnicas para o trabalho, com imagens e sons cativando cada vez mais o interesse do aluno pelo software" (MORAIS, 2003, p. 22).

Mathis (2011) destaca que os softwares podem contribuir com o ensino por investigação, levando a desenvolver o processo de descobertas. Ao realizar uma pesquisa de campo sobre o uso de softwares, a autora contatou a prazerosa participação dos alunos. Segundo ela, a professora utilizava diferentes softwares, respeitando o conhecimento da turma. Na escola pesquisada, a autora listou 26 softwares, de diferentes disciplinas, disponíveis no acervo. Assim, os softwares educativos desenvolvem importante papel em sala de aula, pois em uma única atividade pode associar escrita, desenho, a lógica, o desenvolvimento cognitivo, entre outros fatores.

Vale ressaltar que, não basta disponibilizar softwares para os alunos, pois isso não garante por si só aprendizado. É preciso que o professor conduza a orientação norteando as atividades dos alunos, para que eles sejam estimulados a buscar conhecimento com o uso do computador (MATHIS, 2011).

Cenci e Bonelli (2012) afirmam que a forma com que o software será utilizado é mais importante do que ele mesmo, destacando o insubstituível papel do professor. Desta forma, o software deve ser selecionado de acordo com o trabalho proposto.

Scheffer (2002), ao discutir a respeito do computador na sala de aula, destaca que os softwares podem ampliar a integração dos computadores no currículo, tendo em vista as várias possibilidades de exploração didática, de resolução de problemas, de representação e exploração algébrica que oferecem. Muitos são os programas oferecidos para trabalhar as diferentes disciplinas escolares, contudo, há softwares multidisciplinares e outros mais direcionados para uma disciplina em específico. Em especial no caso da disciplina de Matemática, como exemplo: alguns deles são softwares para o ensino da Geometria, que podem ser usados desde o ensino fundamental, como: Cabri-Geométre e o Geometricks, e outros como Graf Equation, Winplot, Wingeon, Régua e Compasso, Modellus, alguns deles gratuitos. Estes programas de computação possibilitam o traçado de figuras geométricas, a medida de segmentos e ângulos, e outros aspectos do componente geométrico.

A educação não está presa ao computador, ao uso de softwares educativos; a perspectiva é que, na educação, o computador seja utilizado com uma das ferramentas de ensino. E se o computador for usado inadequadamente, pode ser mais destruidor do que "velhos" e "ultrapassados" métodos, comprometendo seriamente a qualidade da educação. A forma como o professor utiliza a tecnologia na sala de aula é que pode mudar a realidade nas escolas. 


\section{Software no ambiente escolar: metodologia}

Os autores deste artigo se propuseram a investigar o uso de sotfwares na prática pedagógica, com o objetivo de verificar como professores na educação básica visualizam a inclusão de tecnologias atuais em sala de aula, enfatizando o uso de softwares. Para a realização da pesquisa foram convidados 30 professores em duas escolas de educação básica na rede pública estadual de ensino da cidade de Cascavel- Paraná-Brasil. Não houve restrição em relação ao nível de ensino e disciplina lecionada. A pesquisa foi realizada com a participação livre e anônima, através da aplicação de um questionário sobre o conhecimento e uso de softwares. Foram devolvidos apenas 20 questionários.

De acordo com Minayo (1994), o questionário é uma técnica de investigação composta por um número mais ou menos elevado de questões, por escrito, às pessoas envolvidas na pesquisa, tendo por objetivo conhecer opiniões específicas. De acordo com Gressler (2004), o questionário possui uma estrutura bem definida, permitindo esclarecimentos, dentro de certos limites. O questionário padronizado busca informações específicas e concisas para as respostas a que se pretende chegar.

A primeira sessão do questionário aplicado aos professores objetivou traçar o perfil do pesquisado, através do levantamento das seguintes informações: disciplina que leciona, tempo de atuação em sala de aula, carga horária semanal e formação inicial. Na segunda e terceira sessão, objetivou-se verificar se o pesquisado já havia tido contato com algum software, se já utilizou durante alguma aula e, em caso afirmativo, a forma com que foi utilizado. Na quarta sessão buscou-se verificar a opinião do pesquisado em relação ao impacto dos softwares na aprendizagem. Na quinta sessão o pesquisado foi convidado a expor as dificuldades e empecilhos, caso houvessem, na introdução de ferramentas tecnológicas nas aulas. Na última sessão, questionou-se a existência de estímulos para o uso de softwares nas aulas.

Os dados e resultados serão apresentados a partir de temas originados nas perguntas do questionário, de forma que a análise será feita conjuntamente. Conforme os dados obtidos e a própria estrutura do questionário, os dados foram enquadrados de forma ampla em três categorias de análise, sendo elas o perfil do pesquisado, o contado e a utilização dos softwares e a percepção dos professores sobre o processo de inserção dos softwares.

\section{Caracterização do perfil dos professores}

Para nortear a pesquisa procurou-se caracterizar o perfil dos professores com a finalidade de possibilitar a melhor compreensão dos dados levantados. Compuseram a amostra professores das seguintes disciplinas: Matemática (5), Química (2), História (2), Inglês (1), Língua Portuguesa (1), Educação Física (2), Geografia (1), Ciências Sociais 
(1), Artes (1), Psicologia (1), Filosofia (1). Professores que lecionam duas disciplinas diferentes: Biologia e Física (1), Matemática e Física (1).

O tempo de atuação dos professores pesquisados em sala de aula pode ser determinado com maior frequência entre quatro a 10 anos. Dentre os respondentes, $45 \%$ deles responderam que atuam entre quatro e 10 anos na educação básica, 25\% responderam ter um tempo de atuação entre 18 e 30 anos,15\% responderam que atuam entre 11 e 18 anos e 15 \% responderam trabalhar numa trajetória menor que três anos.

Os pesquisados possuem características diversificadas em relação à disciplina de atuação e experiência em sala de aula, o que possibilita uma visão ainda mais abrangente em relação ao uso dos softwares. Outra característica importante é que $55 \%$ dos professores trabalham de 26 à 43 horas semanais, 20\% com uma carga horário menor de 20 horas semanais, 15\% entre 44 e 50 horas semanais e 10\% com uma carga horária entre 20 a 25 horas semanais.

Este é um fator muito relevante para a análise dos dados, pois, com uma carga horária excessiva de aulas, o professor possui pouco tempo para o preparo das atividades diárias ou para investir em cursos de capacitação necessários à inserção e utilização de tecnologias no ambiente escolar. Os dados confirmam os de outra pesquisa, em que Santos (2014) defrontou-se com relatos de professores, que julgavam o tempo de hora-atividade insuficiente para estudos e planejamento de atividades diferenciadas, com ou sem o uso de tecnologias.

A relação entre a formação inicial e atuação em sala de aula mostra a maior parte dos professores lecionanado a disciplina de sua formação inicial; apenas três lecionam outras disciplinas, como um professor de Filosofia que leciona a História, e dois professores de Matemática que lecionam Física. É importante frisar que esta não é a realidade de inúmeras escolas brasileiras em que é comum encontrar professores lecionando disciplinas distintas daquela para a qual estão formados, conforme indica a pesquisa de Malacarne (2007).

Através do perfil dos pesquisados, será possível entender melhor as demais questões que norteiam esta pesquisa.

\section{Contato e utilização de software}

As questões dois, três e quatro do questionário objetivaram verificar a familiaridade e utilização de software pelos professores. A segunda questão se referia ao contato com algum software educacional e o momento de sua formação ou atuação em que o docente teve o contato.

Entre os professores pesquisados, $10 \%$ responderam não ter tido contado algum com qualquer tipo de software. Os professores que mencionaram ter tido contato com algum software foram convidados a mencionar em que momento foi. Assim, o contato 
com software foi para 35\% em cursos posteriores a formação inicial de graduação, como pós-graduação ou formação continuada, 30\% na graduação, 10\% no ensino médio, 10\% no $\mathrm{PDE}^{1}$ e $5 \%$ por iniciativa própria. Parcela considerável dos professores teve a oportunidade de desenvolver algum tipo de conhecimento sobre software durante momentos de formação inicial ou continuada ou de pós-graduação que poderiam ser utilizados em suas disciplinas.

Bastos (2010) lembra que a formação docente para uso de tecnologias na educação ainda é recente na América Latina, assim como a modernização das escolas. Ainda que o percentual de professores que tiveram contato com os softwares na graduação seja significativo, ainda é um dado preocupante, já que eles precisam direcionar as aulas para alunos que têm facilidade para manusear aparatos tecnológicos e utilizar internet. $\mathrm{O}$ autor ainda lembra que muitos alunos dispõem de tecnologias mais modernas do que a da escola.

Em relação ao conhecimento de software através de aperfeiçoamento, que foi citado por 35\% dos entrevistados, destaca-se a formação continuada promovida pela Secretaria da Educação do Paraná. As autoras Assis, Czelusniak e Roehrig (2011) constataram que entre os anos de 2007 e 2009 não foram oferecidos cursos destinados ao uso de ferramentas digitais, em especial os softwares para os professores do Paraná; por outro lado, houve incentivos para a utilização de tecnologias através dos Grupos de Trabalhos em Rede (GTR) promovidos pelo Programa de Desenvolvimento Educacional (PDE), mencionado por $10 \%$ dos professores pesquisados. Ainda segundo as autoras, os professores têm interesse em conhecer e aplicar tecnologias em suas aulas, buscando por conta própria o conhecimento que lhes falta.

Dentre os softwares citados pelos participantes da pesquisa estão: dicionários aplicativos, simuladores e jogos para visualização de moléculas, Pluck no planeta dos sons (Dislexia), tabuada, laboratórios virtuais, jogos educativos, Web Question, museus virtuais, Régua e Compasso, Geogebra, softwares para confecção de gráficos, JClic, Poly, Google Arts, Cabri-Geometry, Phet (Simuladores), Modellus, Excel, Applets.

Os softwares mencionados são na grande maioria gratuitos e de fácil acesso. Os softwares como o Modellus, JClic e Poly necessitam de download para ser utilizado - um problema, já que o sistema utilizado nas escolas estaduais do Paraná não permite esse tipo de ação. Ainda na questão relativa ao contato com algum tipo de software, 35\% dos professores que mencionaram ter tido contato não disseram o nome de nenhum e afirmam não recordar. Este dado sugere a pouca ou nenhuma utilização em sala de aula.

A terceira questão abordada se refere à utilização de software em suas aulas. Os professores que citaram não ter tido nenhum conhecimento durante sua formação disseram que também não utilizam nas aulas nenhum tipo de software. Entre os professores que mencionaram ter tido contado com software, 33\% declararam não utilizar tal ferramenta de nenhuma forma com os alunos ou para preparação das aulas. Por outro 
lado, $67 \%$ professores citaram que utilizam os softwares em suas aulas, dentre eles 33,5\% declararam utilizar para fazer a introdução de conteúdos e outros 33,5\% para atividades de fixação, pesquisa, avaliação e atendimento psicopedagógico.

A quarta questão buscou a opinião dos professores sobre a utilização de software e sua interferência na aprendizagem. Entre os pesquisados, $75 \%$ responderam que a utilização de software traz benefícios, 20\% responderam que traz benefícios e prejuízos, e $5 \%$ responderam que não traz benefícios e nem prejuízos. Observa-se nas respostas dos professores que $75 \%$ consideram importante a utilização de software nas aulas, pois traz benefício à aprendizagem dos alunos e que a utilização de recursos complementares auxilia de maneira integrada e inteligente.

Para Miranda (2007) os efeitos positivos do uso de tecnologias na aprendizagem são percebidos apenas pelos professores que dominam as ferramentas e promovem atividades desafiadoras aos alunos. É preciso que o professor utilize as tecnologias para apoiar os alunos na construção do aprendizado, desenvolvendo atividades que integrem as ferramentas tecnológicas de forma criativa aos conteúdos do currículo.

\section{Introdução e estímulo de ferramentas tecnológicas}

As questões finais do questionário ( 5 e 6 ) tiveram como intuito conhecer a opinião do professor sobre a realidade que permeia a introdução de tecnologias na escola. A questão 5 se referia a uma pergunta de opinião, que teve por objetivo saber se existe alguma dificuldade ou empecilho na introdução de ferramentas tecnológicas nas ações docentes. Nesta questão, 95\% dos pesquisados responderam existir alguma dificuldade e $5 \%$ responderam não haver dificuldade ou empecilho para utilização de tecnologias.

Entre os $95 \%$ professores que responderam ter dificuldade e empecilho na introdução de ferramentas tecnológicas, todos citaram a infraestrutura da escola como principal fator, e em conjunto com este citaram a falta de interesse dos alunos, a falta de domínio das ferramentas tecnológicas, indisciplina dos alunos, falta de incentivo. Outro fator mencionado por $16 \%$ dos professores foi a ausência de pessoal disponível para dar suporte técnico (conserto, problemas com a internet), além da falta de formação continuada sobre o tema e o uso frequente do laboratório de informática para outras atividades, com pouca disponibilidade para agendamento de aulas.

Em pesquisa realizada por Santos (2014) também foi possível constatar a percepção dos professores sobre a precariedade da estrutura das escolas estaduais para inserção de tecnologias. Questões como falta de investimento na manutenção dos laboratórios de informática e a precariedade em seu funcionamento são discutidos pela autora.

A última pergunta objetivou saber se existe algum estímulo e por parte de quem para uso de softwares nas aulas. Para $60 \%$ o estímulo maior é por parte dos governos federal e estadual; $15 \%$ responderam que o estímulo parte da direção da escola, dos 
alunos, dos próprios colegas professores; $10 \%$ desconhecem a existência de incentivo; para 5\% o maior incentivador é o Núcleo Regional de Educação, através de cursos de capacitação dos professores; $5 \%$ diz não haver estímulo, e por fim $5 \%$ não responderam.

Os dados nos remontam a uma série de preocupações, pois segundo os professores a utilização de ferramentas tecnológicas traz benefícios ao aprendizado do aluno, tendo em vista que 12 as utilizam de alguma forma na elaboração das aulas, ao passo que 95\% citaram a falta de infraestrutura - e este é um fator relevante no aspecto motivador do professor, pois para que ele efetive seu trabalho com qualidade e êxito, é necessário que se tenha uma infraestrutura de qualidade, computadores que estejam funcionando, sinal de internet, programas que rodem com qualidade. Mesmo havendo estímulo por parte do governo federal e estadual ou outras instâncias, segundo os pesquisados, a infraestrutura das escolas deixa a desejar.

Outro ponto de destaque é em relação à carente formação docente acerca das ferramentas tecnológicas. Muitos professores disseram não introduzir em suas aulas pela falta de conhecimento e domínio. Os alunos possuem na grande maioria uma facilidade no manuseio e conhecimento de certas ferramentas tecnológicas, logo, os professores se sentem receosos ao utilizá-las, tendo em vista que muitos, em uma longa trajetória de magistério sem ter tido contato com as tecnologias durante a graduação, se sentem frustrados quanto à imersão recente no ambiente digital, acabando por gerar resistências.

A popularização das novas tecnologias faz com que os alunos estejam cada vez mais distantes da motivação ao participar de aulas no perfil tradicional de ensino. Com isso, é importante que o professor incorpore tendências atuais, saia do seu espaço inercial e procure capacitar-se, integrando os recursos tecnológicos às práticas pedagógicas para que desperte o interesse do aluno em aprender.

O professor precisa ser reflexivo e se questionar sobre os objetivos a serem alcançados. É necessário desenvolver "[...] um debate sobre a relevância das tecnologias no trabalho docente e sobre a melhor maneira de usá-las, para que não sejam vistas e trabalhadas como um recurso meramente técnico" (ROSA, p.221, 2013).

Os cursos de formação docente são uma alternativa para criar oportunidades e mudar o quadro atual das escolas, por isso é necessário criar condições para desenvolver competências no uso de ferramentas digitais com visão crítica e contextualizada da realidade, explorando os aspectos técnicos e pedagógicos, norteadores da reconstrução do conhecimento como forma de relacionar a informação à prática formativa.

\section{Considerações finais}

A tecnologia no cotidiano pode contribuir com o trabalho docente. Quando utilizado de forma adequada, pode ser importante ferramenta para motivar os alunos e 
melhorar a qualidade do ensino. A formação do aluno como cidadão ativo no meio em que vive não pode ficar à margem da evolução tecnológica na qual a sociedade está mergulhada atualmente.

Todavia, inserir a tecnologia não garante ensino de qualidade. Ela precisa ser associada a uma ação docente bem planejada e estruturada. Desta forma, poderá contribuir muito para uma aprendizagem significativa. $O$ professor não precisa temer a perda de função neste contexto, já que continua sendo um importante sujeito na mediação do conhecimento. Mas o que precisa ficar claro é que ele precisa estar continuamente se atualizando para obter o domínio das tecnologias inseridas na escola.

É importante ressaltar que as tecnologias não trarão mudanças significativas para a educação, caso seu uso não esteja atrelado a políticas de valorização dos professores, de melhoria na qualidade de materiais didáticos e do pleno envolvimento do trabalho docente.

O que se espera é a conscientização de que, embora ainda haja dificuldades em se perceber a modernização no ensino, assim como é visto em outras áreas a educação está passando por um momento histórico diferenciado em que as tecnologias estão cada vez mais acessíveis para pessoas de diferentes classes sociais. Investimentos financeiros e em formação continuada para os professores são fundamentais. Somente assim haverá ensino de qualidade e uma sociedade com formação crítico-científico adequada.

Recebido em 18/07/2016, reapresentado em 26/10/2016 e aprovado em 04/11/2016

\section{Notas}

1 O Programa de Desenvolvimento Educacional - PDE do Paraná configura um espaço de educação continuada que tem o objetivo de proporcionar aos professores da rede pública estadual subsídios teórico-metodológicos para o desenvolvimento de ações educacionais sistematizadas, e que resultem em redimensionamento de sua prática.

\section{Referências}

ASSIS, Kleine Karol; CZELUSNIAK, Sonia Maris; ROEHRIG, Silmara Alessi Guebur. A articulação entre o ensino de ciências e as TIC: desafios e possibilidades para a formação continuada. In. Anais do I seminário Internacional de Representações Sociais, Subjetividade e Educação - SIRSEE. 2011.

BASTOS, Maria Inês. O desenvolvimento de competências em TIC para a educação na formação de docentes na América Latina. Formação de Competências em TIC de Docentes na AL. Versão preliminar. 2010. 
BIELSCHOWSKY, Carlos Eduardo. Tecnologia da informação e comunicação das escolas públicas brasileiras: o programa proinfo integrado. Revista E-Curriculum, v. 5, n.1, 2009. Disponível em <http:// revistas.pucsp.br/index.php/curriculum/article/view/3256/2174>. Acesso em Outubro de 2015.

CENCI, Danielle; BONELLI, Sonia Maria Souza. Critérios para Avaliação de Softwares Educacionais. In: Anais IX ANPED SUL. Seminário de Pesquisa em Educação da Região Sul. 2012.

CHAVES, Eduardo. Tecnologia e Educação: O Futuro da Escola na Sociedade da Informação. Campinas, SP. Mindware Editora. Dezembro de 1998.

FERREIRA, Ana Lucia Duarte. Informática Educativa na Educação Infantil: riscos e benefícios. Monografia. Universidade Federal do Ceará. 2002. Disponível em <http://www.multimeios.ufc.br/ arquivos/pc/monografias/Monografia_lucia.pdf> Acesso em Junho de 2014.

FERREIRA, Vitor. As Tecnologias Interativas no Ensino. Química Nova, v. 21, n. 6. 1998. Disponível em <http://www.scielo.br/pdf/qn/v21n6/2913.pdf.> Acesso em Agosto de 2013.

GONTIJO, Flávia Lamounier; COSTA, José Wilson. Uma Experiência com Software Educativo na Escola: A Tecnologia e a Prática Pedagógica em Discussão. Revista Educação e Tecnologia, Belo Horizonte, v. 13, n. 2, p. 96-100, maio./ago. 2008. Disponível em <http://www.senept.cefetmg.br/ galerias/Arquivos_senept/anais/terca_tema5/TerxaTema5Artigo11.pdf> Acesso em junho de 2014.

GRESSLER, Lori Alice. Introdução à pesquisa: projetos e relatórios. 2ª Edição. Revisão Atualizada. São Paulo. Loyola, 2004.

LEITE, Werlayne Stuart Soares; RIBEIRO, Carlos Augusto do Nascimento. A inclusão das TICS na educação brasileira: problemas e desafios. Revista Internacional de Investigacion en Educacion, $\mathbf{v}$. 5, n. 10, 2012. Disponível em: <http://magisinvestigacioneducacion.javeriana.edu.co/> . Acesso em Outubro de 2015.

MALACARNE, Vilmar. Os professores de química, física e biologia da Região Oeste do Paraná: formação e atuação. 2007. 253p. Tese (Doutorado) - Faculdade de Educação da Universidade de São Paulo, São Paulo.

MATHIS, Sonia da Penha Barbosa. Estudo de Caso do Uso dos Softwares Educacionais na Escola Municipal Eça de Queirós. Lucas do Rio Verde - MT. Monografia. Universidade Federal de Mato Grosso. 2011.

MINAYO, Maria Cecília de Souza. O desafio do conhecimento: pesquisa qualitativa em saúde. Rio de Janeiro, Hucitec-Abrasco, 2007.

MIRANDA, Guilhermina Lobato. Limites e possibilidades das TIC na educação. Revista de ciências da educação. № 03. Maio / Agosto de 2007.

MORAIS, Rommel Xenofonte Teles. Software Educacional: A Importância de sua Avaliação e do seu Uso nas Salas de Aula. Monografia. Faculdade Lourenço Filho. 2003.

PEREIRA, Ana Maria. Tecnologia X Educação. Monografia. Universidade Cândido Mendes. Rio de Janeiro. 2011. Disponível em <http://www.avm.edu.br/docpdf/monografias_publicadas/C203090.pdf.> Acesso em agosto de 2013.

ROSA, Rosemar. Trabalho docente: dificuldades apontadas pelos professores no uso das tecnologias. Revista Encontro de Pesquisa em Educação, Uberaba, v. 1, n.1, p. 214-227, 2013. Disponível em:< http://revistas.uniube.br/index.php/anais/article/viewFile/710/1007>. Acesso em setembro de 2016. 
SANTOS, Francisléia Giacobbo. A percepção e a ação docente: enfoques teórico-práticos decorrentes do uso das tecnologias de informação e comunicação (TIC) na educação. Dissertação. Universidade Estadual do Oeste do Paraná. 2014.

SCHEFFER, Nilce Fátima. Corpo - Tecnologias - Matemática: uma interação possível no Ensino Fundamental. Erechim: Edifapes, 2002.

VALENTE, José Armando. O computador na sociedade do conhecimento. Campinas, SP: Nied, 2002. 